Check for updates

Cite this: J. Mater. Chem. A, 2018, 6, 6251

Received 31st January 2018 Accepted 13th March 2018

DOI: $10.1039 /$ c8ta01059e

rsc.li/materials-a

\section{Substituted thiadiazoles as energy-rich anolytes for nonaqueous redox flow cells $\uparrow$}

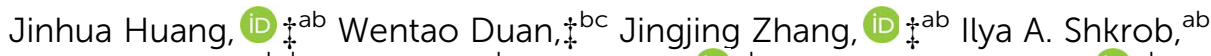 \\ Rajeev S. Assary, ${ }^{\text {bd }}$ Baofei Pan, ${ }^{\text {ab }}$ Chen Liao, (D) ${ }^{\text {ab }}$ Zhengcheng Zhang, (D) ab \\ Xiaoliang Wei ${ }^{*} \S^{* \mathrm{bc}}$ and Lu Zhang (D)*ab
}

Understanding structure-property relationships is essential for designing energy-rich redox active organic molecules (ROMs) for allorganic redox flow batteries. Herein we examine thiadiazole ROMs for storage of negative charge in the flow cells. These versatile molecules have excellent solubility and low redox potentials, allowing high energy density to be achieved. By systematically incorporating groups with varying electron accepting/withdrawing ability, we have examined substituent effects on their properties of interest, including redox potentials, calendar lives of charged ROMs in electrolyte, and the flow cell cycling performance. While the calendar life of energized fluids can be tuned in a predictable fashion over a wide range, the improvements in the calendar life do not automatically translate into the enhanced cycling performance, indicating that in addition to the slow reactions of charged species in the solvent bulk, there are other parasitic reactions that occur only during the electrochemical cycling of the cell and can dramatically affect the cycling lifetime.

Redox flow batteries (RFBs) are promising candidates for electrochemical energy storage in the flexible electric grid of the future. ${ }^{1-3}$ With charged fluids circulating between the storage tanks and power-generating stacks, decoupling of energy storage and power generation can be achieved. Due to this decoupling, customized designs of RFBs can satisfy a wide range of energy/power requirements. ${ }^{4-7}$ The energy density of a flow cell ${ }^{8}$ is the product of the charge on the carrier, the cell voltage, and the concentration of the carriers. Maximizing this

${ }^{a}$ Chemical Sciences and Engineering Division, Argonne National Laboratory, USA. E-mail: luzhang@anl.gov

${ }^{b} J o i n t$ Center for Energy Storage Research, USA. E-mail: xwei18@iupui.edu

${ }^{c}$ Pacific Northwest National Laboratory, USA

${ }^{d}$ Materials Science Division, Argonne National Laboratory, USA

$\dagger$ Electronic supplementary information (ESI) available: Synthesis procedures of derivative molecules, static electrolysis, details of EPR spectroscopy and electrochemical tests. See DOI: 10.1039/c8ta01059e

\$ These authors contributed equally.

$\S$ Present Address: Department of Mechanical and Energy Engineering, Indiana University-Purdue University Indianapolis (IUPUI), 799 W. Michigan St, Indianapolis, IN 46202. energy density is essential for lowering the costs. ${ }^{9,10}$ Increasing the concentration is the easiest way to achieve this goal without changing the cell chemistry, ${ }^{\mathbf{1 1}, \mathbf{1 2}}$ but another way to the same end is increasing the cell voltage. While zinc based aqueous RFBs could surpass the electrolysis potential of water, ${ }^{\mathbf{1 3}, 14}$ the narrow electrochemical window of the typical aqueous solutions limits the latter to $<1.5 \mathrm{~V}$, and surpassing this inherent limitation requires nonaqueous electrolytes. ${ }^{\mathbf{1 5 , 1 6}}$

Both metal-based complexes and redox active organic molecules (ROMs) have been used for charge storage in such systems. ${ }^{17-19}$ ROMs in the positive and negative compartments of a RFB are referred to as catholyte and anolyte molecules, respectively, and the cell voltage is defined by the difference in their redox potentials. Thus, maximization of the voltage requires using ROMs at the extremes of the redox potential range that also need to be stable in solution when charged, which is a difficult requirement to meet. For this reason, the present selection of energy dense ROMs remains limited, while the achieved energy density and cycling stability are still insufficient. $^{\text {20-23 }}$ Therefore, designing better ROMs is a high priority. ${ }^{24-28}$

Finding suitable anolytes with the lowest redox potentials proved to be an especially daunting task, as the corresponding radical anions tend to be overly reactive. In this regard, thiadiazoles have been recognized ${ }^{29}$ as an exceptional class of molecules yielding uncommonly stable radical anions that can be used to store negative charge in RFBs.

In this report, we examine several thiadiazole ROMs that are based on 2,1,3-benzothiadiazole (BzNSN), 1 (Fig. 1), by systematically varying the substituent groups in the arene ring. An anolyte in nonaqueous RFBs needs to meet several property requirements including a low reduction potential, high solubility, low molecular weight, etc. What makes BzNSN unique is that it surpasses almost all other anolytes in terms of most of these key properties (see Table $\mathbf{S} 1 \dagger$ ). The progenitor compound $\mathbf{1}$ is known to yield a stable radical anion when chemically or electrochemically reduced. When coupled with 2,5-di-tert-butyl1-methoxy-4-(2'-methoxyethoxy)-benzene (DBMMB in Fig. 1), ${ }^{23,30}$ 
<smiles>[R]c1ccc2nsnc2c1</smiles><smiles>COCCOc1cc(C(C)(C)C)c(OC)cc1C(C)(C)C</smiles>

R-BzNSN

DBMMB

Fig. 1 Structural formulas for 2,1,3-benzothiadiazole (R-BzNSN) derivatives and DBMMB. The substituent group $\mathrm{R}$ is $\mathrm{H}$ (1), $\mathrm{CH}_{3}$ (2), $\mathrm{OCH}_{3}(3), \mathrm{F}(4)$, and $\mathrm{CF}_{3}(5)$.

1 yields cell voltages of $\sim 2.4 \mathrm{~V}$ and reasonable cycling at high concentrations $(0.1-0.5 \mathrm{M}){ }^{30}$

Since BzNSN can be easily derivatized, ${ }^{31}$ a natural question to ask is whether the performance of $\mathbf{1}$ in the RFBs can be improved further through tuning of the electronic properties of this molecule.

To address this question, four functional groups were introduced into 1 at the carbon-5 atom as shown in Fig. 1 using the synthetic procedures outlined in Section S1 in the ESI (see Fig. S1 to S7 in the ESI $\uparrow$ for spectroscopic data): a weak (2) and a strong (3) electron donating group and a weak (4) and a strong (5) electron withdrawing group. All of these molecules have excellent solubility in the acetonitrile based electrolytes (>2 M). The redox behaviors were evaluated using cyclic voltammetry

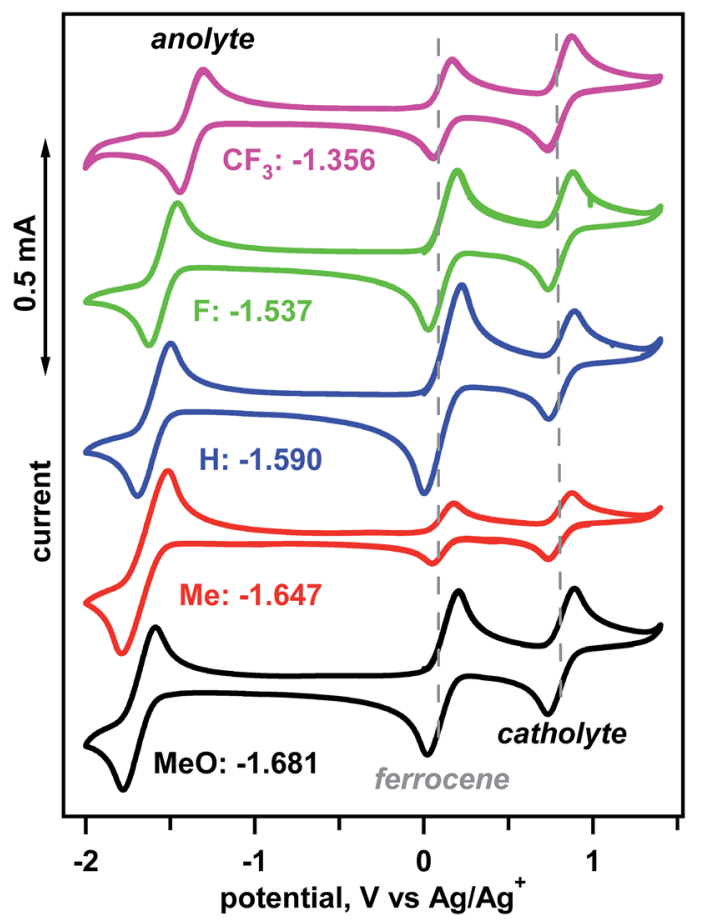

Fig. 2 Tuning of the redox potential for BzNSN derivatives (the halfwave potential $E_{1 / 2} \mathrm{vs} . \mathrm{Ag} / \mathrm{Ag}^{+}$is given in the plot) by changing the substituent group R- at carbon-5 of BzNSN. DBMMB catholyte and ferrocene were used as the internal references (both gray dashed lines). Cyclic voltammetry of $50 \mathrm{mM}$ ROMs (each) in acetonitrile containing $0.5 \mathrm{M}$ LiTFSI $\left(0.2 \mathrm{~V} \mathrm{~s}^{-1}\right)$. The wave at $0.815 \mathrm{~V} v \mathrm{vs} . \mathrm{Ag} / \mathrm{Ag}^{+}$ corresponds to anodic oxidation of DBMMB. The CV plots have been stacked to facilitate comparison. with DBMMB and ferrocene serving as the internal references in acetonitrile containing $0.5 \mathrm{M}$ solution of lithium bis(trifluoromethanesulfonyl) imide (LiTFSI). As shown in Fig. 2, the half-wave redox potential $E_{1 / 2}$ changes as the substituent varies. Density functional theory calculations indicated that the derivatization would change the energetics of the lowest unoccupied molecular orbitals and the reduction potentials in a specific way, as shown in Fig. S8 in the ESI. $\dagger$ In full accord with these theoretical predictions, as the electron withdrawing effect decreases and donating effect increases, the redox potentials decrease from $-1.356 \mathrm{~V} v s$. $\mathrm{Ag} / \mathrm{Ag}^{+}$for 5 to $-1.681 \mathrm{~V} v s$. $\mathrm{Ag} / \mathrm{Ag}^{+}$ for 3. The highest value corresponds to the strong electron withdrawing $-\mathrm{CF}_{3}$ group and the lowest value corresponds to the strong electron donating-OMe group.

To characterize the calendar life stability of charged thiadiazole ROMs in the same electrolyte, these ROMs $(50 \mathrm{mM}$ anolyte and $50 \mathrm{mM}$ catholyte) were charged to $100 \%$ in an electrochemical $\mathrm{H}$ cell (see Section S2 and Fig. S9 in the ESI $\dagger$ for more details). Electron paramagnetic resonance (EPR) spectroscopy was used to monitor the decay kinetics for the electrochemically generated radical anions. The radical anion of $\mathbf{5}$ was short-lived ( $<15 \mathrm{~min})$ possibly due to fluorine loss from the trifluoromethyl group. The half-decay lifetimes $t_{1 / 2}$ of radical anions of other thiadiazole ROMs are shown in Fig. 3 (under the same experimental conditions, the $t_{1 / 2}$ for the radical cation of DBMMB was $c a .230$ h, see Fig. S9(a) in the ESI $\dagger$ ). It is seen from Fig. 3 that there is a linear correlation between the logarithm of the lifetime of an anolyte radical anion and the redox potential of the corresponding parent ROM. Therefore, the calendar lives of charged cell fluids decrease exponentially as the redox potentials of the ROMs become more negative, which indicates that the redox potentials of the ROMs and chemical stabilities

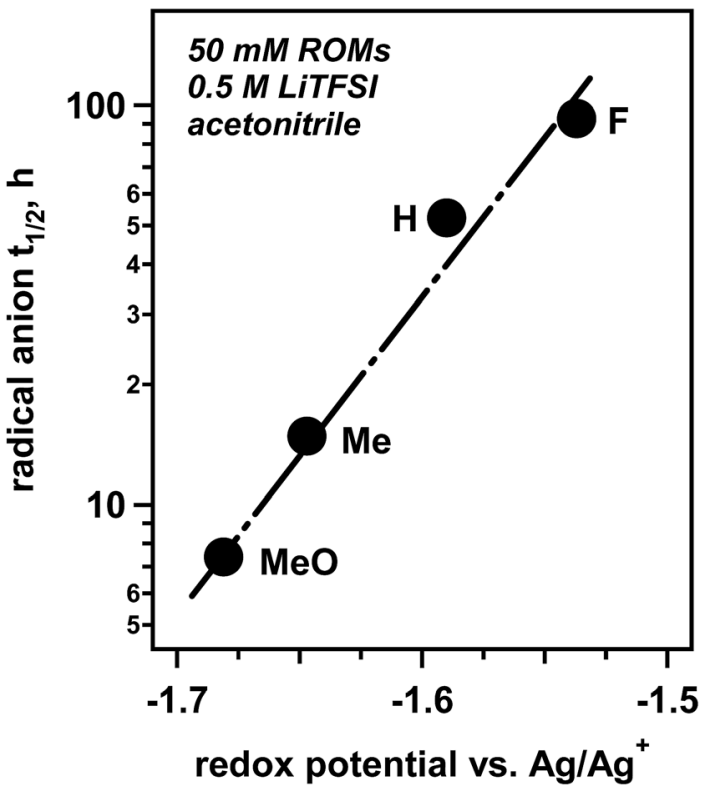

Fig. 3 Correlation of the half-decay lifetime $t_{1 / 2}$ of the radical anions for BzNSN derivatives shown in Fig. 1 with the redox potentials $E_{1 / 2}$ of the parent ROMs given in Fig. $2(50 \mathrm{mM}$ ROMs each, $0.5 \mathrm{M}$ LiTFSI in acetonitrile). Note the logarithmic vertical scale. 
of their reduced states are two opposing factors that need to be carefully balanced when designing a new molecule. The greatest stability is observed for the radical anion of $\mathbf{4}$, whose redox potential is the highest. Since the half-decay lifetimes of these radical anions are less than the half-life of the radical cations of DBMMB in the same solutions (see above), we expect that cycling performance would be mainly determined by the stability of the reduced anolyte ROMs.

To assess the performance of these ROMs in a realistic setting, flow cell cycling was conducted using mixed anolyte and catholyte ROMs in each compartment with the same supporting electrolyte as in Fig. 2 and 3 (see Section S3 in the ESI $\dagger$ for more details). As seen from Fig. 4, the derivatization of 1 leads to improvements over the parent compound. In contrast to the calendar life trends shown in Fig. 3, all the derivatized BzNSN compounds delivered a better cycling performance compared to 1. The best performer was compound 2 , which demonstrated $75 \%$ capacity retention after 100 cycles. Other derivatives, including the most stable anolyte 4, delivered only $64-65 \%$ capacity retentions, which are only slightly better than $62 \%$ of 1 . It is noted that the cycling performance was also evaluated using a static $\mathrm{H}$ cell, for which the results were once again different from the trends shown in Fig. 3 but also different from the trends shown in Fig. 4 (see Fig. S12 $\dagger$ ). These inconsistent cycling lifetimes suggest that apart from the reactions of charged radical ions in the solvent bulk, there are additional parasitic reactions that affect the performance, which occur only when the cells are continually cycled, and these parasitic reactions strongly depend on the specific cell design and the mode of operation. Understanding the causes for poor correlation between the calendar and cycling lives of the charged fluids requires more studies to identify and control these unwanted processes.

To conclude, thiadiazole compounds are among the select group of anolyte ROMs that can potentially deliver sufficient energy density for all-organic RFBs to become competitive with aqueous flow cells. Our studies suggest that the stability of their radical anions (that is, charged ROMs) in acetonitrile solutions

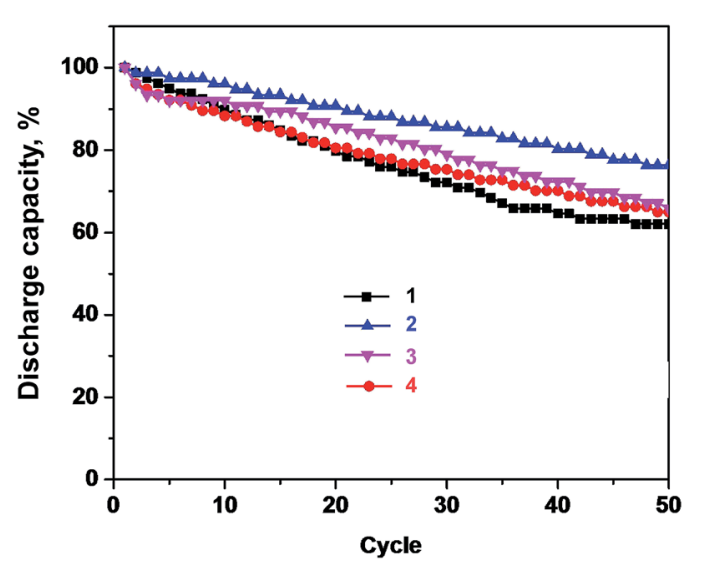

Fig. 4 Capacity fade profile (discharge capacity as the percentage of the initial capacity) as a function of cycle number for flow cells containing 0.1 M ROMs each in acetonitrile (1.0 M LiTFSI). See the color legend for disambiguation. correlates well with the redox potential of the corresponding parent compounds. However, the cycle lives of these anolyte ROMs in the RFB cells did not follow the calendar life trends suggesting the occurrence of additional parasitic reactions, which do not occur during calendar aging of the same charged fluids. An incremental improvement in the cycling performance was obtained for the 2/DBMMB system over our current benchmark 1/DBMMB system.

Thus, combining the high cell voltage $(>2.4 \mathrm{~V})$ with the long cycling life $(>1000 \mathrm{~h})$ in all-organic RFBs remains a challenge, as it is the natural tendency of the radical ions to become exponentially more reactive as the redox potential reaches the extremes, as illustrated in Fig. 3. With these molecules we are on the very edge of possibility, reaching the compromise between the highest energy density and the stability of the radical anion that can be achieved in acetonitrile. This finding strongly indicates the significant role of structural engineering in achieving the improvement of radical ion stability, suggesting a generic guidance for developing long-cycling ROM-based flow cells.

\section{Conflicts of interest}

The authors declare no competing financial interests.

\section{Acknowledgements}

This research was financially supported by the Joint Center for Energy Storage Research (JCESR), an Energy Innovation Hub funded by the U.S. Department of Energy, Office of Science, and Basic Energy Sciences. PNNL is a multi-program national laboratory operated by Battelle for DOE under Contract DEAC05-76RL01830. The submitted manuscript has been created by UChicago Argonne, LLC, Operator of Argonne National Laboratory ("Argonne"). Argonne, a U.S. Department of Energy Office of Science laboratory, is operated under Contract No. DEAC02-06CH11357. The U.S. Government retains for itself, and others acting on its behalf, a paid-up nonexclusive, irrevocable worldwide license in said article to reproduce, prepare derivative works, distribute copies to the public, and perform publicly and display publicly, by or on behalf of the Government.

\section{References}

1 B. Dunn, H. Kamath and J.-M. Tarascon, Electrical Energy Storage for the. Grid: A Battery of choices, Science, 2011, 334, 928-935.

2 Z. Yang, J. Zhang, M. C. W. Kintner-Meyer, X. Lu, D. Choi, J. P. Lemmon and J. Liu, Electrochemical energy storage for green grid, Chem. Rev., 2011, 111, 3577-3613.

3 X. Wei, W. Pan, W. Duan, A. Hollas, Z. Yang, B. Li, Z. Nie, J. Liu, D. Reed, W. Wang and V. Sprenkle, Materials and Systems for Organic Redox Flow Batteries: Status and Challenges, ACS Energy Lett., 2017, 2, 2187-2204.

4 A. Weber, M. Mench, J. Meyers, P. Ross, J. Gostick and Q. Liu, Redox flow batteries: a review, J. Appl. Electrochem., 2011, 41, 1137-1164. 
5 M. Skyllas-Kazacos, M. H. Chakrabarti, S. A. Hajimolana, F. S. Mjalli and M. Saleem, Progress in Flow Battery Research and Development, J. Electrochem. Soc., 2011, 158, R55-R79.

6 P. Leung, X. Li, C. Ponce de Leon, L. Berlouis, C. T. J. Low and F. C. Walsh, Progress in redox flow batteries, remaining challenges and their applications in energy storage, $R S C$ Adv. , 2012, 2, 10125-10156.

7 W. Wang, Q. Luo, B. Li, X. Wei, L. Li and Z. Yang, Recent progress in redox flow battery research and development, Adv. Funct. Mater., 2013, 23, 970-986.

8 Q. Huang and Q. S. Wang, Next-Generation, High-EnergyDensity Redox Flow Batteries, ChemPlusChem, 2015, 80, 312-322.

9 R. M. Darling, K. G. Gallagher, J. A. Kowalski, S. Haac and F. R. Brushettad, Pathways to low-cost electrochemical energy storage: a comparison of aqueous and nonaqueous flow batteries, Energy Environ. Sci., 2014, 7, 3459-3477.

10 V. Viswanathan, A. Crawford, D. Stephenson, S. Kim, W. Wang, B. Li, G. Coffey, E. Thomsen, G. Graff, P. Balducci, M. Kintner-Meyer and V. Sprenkle, Cost and performance model for redox flow batteries, J. Power Sources, 2014, 247, 1040-1051.

11 M. Skyllas-Kazacos, M. Rychcik, R. G. Robins, A. G. Fane and M. A. Green, New All-Vanadium Redox Flow Cell, J. Electrochem. Soc., 1986, 133, 1057-1058.

12 L. Li, S. Kim, W. Wang, M. Vijayakumar, Z. Nie, B. Chen, J. Zhang, G. Xia, J. Hu, G. Graff, J. Liu and Z. Yang, A Stable Vanadium Redox-Flow Battery with High Energy Density for Large-Scale Energy Storage, Adv. Energy Mater., 2011, 1, 394-400.

13 S. Gu, K. Gong, E. Z. Yan and Y. Yan, A multiple ion-exchange membrane design for redox flow batteries, Energy Environ. Sci., 2014, 7(9), 2986-2998.

14 K. Gong, X. Ma, K. M. Conforti, K. J. Kuttler, J. B. Grunewald, K. L. Yeager, M. Z. Bazant, S. Gu and Y. Yan, A zinc-iron redox-flow battery under $\$ 100$ per $\mathrm{kW}$ h of system capital cost, Energy Environ. Sci., 2015, 8(10), 2941-2945.

15 S.-H. Shin, S.-H. Yun and S.-H. Moon, A review of current developments in non-aqueous redox flow batteries: characterization of their membranes for design perspective, RSC Adv., 2013, 3, 9095-9116.

16 K. Gong, Q. Fang, S. Gu, S. F. Y. Li and Y. Yan, Nonaqueous redox-flow batteries: organic solvents, supporting electrolytes, and redox pairs, Energy Environ. Sci., 2015, 8, 3515-3530.

17 Y. Matsuda, K. Tanaka, M. Okada, Y. Takasu, M. Morita and T. Matsumura-Inoue, A rechargeable redox battery utilizing ruthenium complexes with non-aqueous organic electrolyte, J. Appl. Electrochem., 1988, 18, 909-914.

18 Q. Liu, A. E. S. Sleightholme, A. A. Shinkle, Y. Li and L. T. Thompson, Non-aqueous vanadium acetylacetonate electrolyte for redox flow batteries, Electrochem. Commun., 2009, 11, 2312-2315.

19 H. D. Pratt III, D. Ingersoll, N. S. Hudak, B. B. McKenzie and T. M. Anderson, Copper ionic liquids: Tunable ligand and anion chemistries to control electrochemistry and deposition morphology, J. Electroanal. Chem., 2013, 704, 153-158.

20 Z. Li, S. Li, S. Liu, K. Huang, D. Fang, F. Wang and S. Peng, Electrochemical Properties of an All-Organic Redox Flow Battery Using 2,2,6,6-Tetramethyl-1-Piperidinyloxy and $\mathrm{N}$ Methylphthalimide, Electrochem. Solid-State Lett., 2011, 14, A171-A173.

21 F. R. Brushett, J. T. Vaughey and A. N. Jansen, An All-Organic Non-aqueous Lithium-Ion Redox Flow Battery, Adv. Energy Mater., 2012, 2, 1390-1396.

22 S. H. Oh, C. W. Lee, D. H. Chun, J. D. Jeon, J. Shim, K. H. Shin and J. H. Yang, A metal-free and all-organic redox flow battery with polythiophene as the electroactive species, $J$. Mater. Chem. A, 2014, 2, 19994-19998.

23 J. Huang, L. Cheng, R. S. Assary, P. Wang, Z. Xue, A. K. Burrell, L. A. Curtiss and L. Zhang, Liquid Catholyte Molecules for Nonaqueous Redox Flow Batteries, Adv. Energy Mater., 2015, 5, 1401782.

24 E. V. Carino, C. E. Diesendruck, J. S. Moore, L. A. Curtiss, R. S. Assary and F. R. Brushett, $\mathrm{BF}_{3}$-promoted electrochemical properties of quinoxaline in propylene carbonate, $R S C$ Adv., 2015, 5, 18822-18831.

25 C. S. Sevov, R. E. M. Brooner, E. Chénard, R. S. Assary, J. S. Moore, J. Rodríguez-López and M. S. Sanford, Evolutionary Design of Low Molecular Weight Organic Anolyte Materials for Applications in Nonaqueous Redox Flow Batteries, J. Am. Chem. Soc., 2015, 137, 14465-14472.

26 X. Wei, L. Cosimbescu, W. Xu, J. Z. Hu, M. Vijayakumar, J. Feng, M. Y. Hu, X. Deng, J. Xiao, J. Liu, V. Sprenkle and W. Wang, Towards high-performance nonaqueous redox flow electrolyte via ionic modification of active species, Adv. Energy Mater., 2015, 5, 1400678.

27 W. Wang, W. Xu, L. Cosimbescu, D. Choi, L. Li and Z. Yang, Anthraquinone with Tailored Structure for Nonaqueous Metal-Organic Redox Flow Battery, Chem. Commun., 2012, 48, 6669-6671.

28 C. S. Sevov, D. P. Hickey, M. E. Cook, S. G. Robinson, S. Barnett, S. D. Minteer, M. S. Sigman and M. S. Sanford, Physical Organic Approach to Persistent, Cyclable, LowPotential Electrolytes for Flow Battery Applications, J. Am. Chem. Soc., 2017, 139, 2924-2927.

29 N. M. Atherton, J. N. Ockwell and R. Dietz, Electron Spin Resonance and Polarographic Studies of the Radical Anions of Some Nitrogen- and Sulphur-Containing Heterocyclic Molecules, J. Chem. Soc. A, 1967, 771-777.

30 W. Duan, J. Huang, J. A. Kowalski, I. A. Shkrob, M. Vijayakumar, E. Walter, B. Pan, Z. Yang, J. D. Milshtein, B. Li, C. Liao, Z. Zhang, W. Wang, J. Liu, J. S. Moore, F. R. Brushett, L. Zhang and X. Wei, "Wine-Dark Sea" in an Organic Flow Battery: Storing Negative Charge in 2,1,3Benzothiadiazole Radicals Leads to Improved Cyclability, ACS Energy Lett., 2017, 2, 1156-1161.

31 M. Helgesen, S. A. Gevorgyan, F. C. Krebs and R. A. J. Janssen, Substituted 2,1,3-Benzothiadiazole- and Thiophene-Based Polymers for Solar Cells - Introducing a New Thermocleavable Precursor, Chem. Mater., 2009, 21(19), 4669-4675. 